\title{
Acetylated Hyaluronic Acid: Enhanced Bioavailability and Biological Studies
}

\author{
Carmela Saturnino, ${ }^{1}$ Maria Stefania Sinicropi, ${ }^{2}$ Ortensia Ilaria Parisi, ${ }^{2,3}$ \\ Domenico Iacopetta, ${ }^{2}$ Ada Popolo, ${ }^{1}$ Stefania Marzocco, ${ }^{1}$ Giuseppina Autore, ${ }^{1}$ \\ Anna Caruso, ${ }^{2,3}$ Anna Rita Cappello, ${ }^{2}$ Pasquale Longo, ${ }^{4}$ and Francesco Puoci ${ }^{2}$ \\ ${ }^{1}$ Department of Pharmacy, University of Salerno, Via Giovanni Paolo II 132, 84084 Fisciano, Italy \\ ${ }^{2}$ Department of Pharmacy, Health and Nutritional Sciences, University of Calabria, 87036 Arcavacata di Rende, Italy \\ ${ }^{3}$ Department of Computer Engineering, Modeling, Electronics and Systems, University of Calabria, 87036 Rende, Italy \\ ${ }^{4}$ Department of Sciences, University of Salerno, Via Giovanni Paolo II 132, 84084 Fisciano, Italy
}

Correspondence should be addressed to Carmela Saturnino; saturnino@unisa.it and Maria Stefania Sinicropi; s.sinicropi@unical.it

Received 28 February 2014; Accepted 25 June 2014; Published 8 July 2014

Academic Editor: Michela Ori

Copyright (C) 2014 Carmela Saturnino et al. This is an open access article distributed under the Creative Commons Attribution License, which permits unrestricted use, distribution, and reproduction in any medium, provided the original work is properly cited.

\begin{abstract}
Hyaluronic acid (HA), a macropolysaccharidic component of the extracellular matrix, is common to most species and it is found in many sites of the human body, including skin and soft tissue. Not only does HA play a variety of roles in physiologic and in pathologic events, but it also has been extensively employed in cosmetic and skin-care products as drug delivery agent or for several biomedical applications. The most important limitations of HA are due to its short half-life and quick degradation in vivo and its consequently poor bioavailability. In the aim to overcome these difficulties, HA is generally subjected to several chemical changes. In this paper we obtained an acetylated form of HA with increased bioavailability with respect to the HA free form. Furthermore, an improved radical scavenging and anti-inflammatory activity has been evidenced, respectively, on ABTS radical cation and murine monocyte/macrophage cell lines (J774.A1).
\end{abstract}

\section{Introduction}

Hyaluronic acid (HA), the main component of the glycosaminoglycans, is a linear biodegradable polymer with high molecular weight consisting of disaccharide units of $\mathrm{N}$ acetylglucosamine and $D$-glucuronic acid, connected alternately by $\beta 1-3$ and 1-4 glycosidic bonds. HA is naturally present in almost all body fluids and tissues such as the synovial fluid, eye vitreous humor, connective, epithelial, and neural tissues and plays important biological functions in wound healing regulating cell adhesion, motility, differentiation, and proliferation. HA assists the early phases of the inflammatory process, improving cell infiltration and facilitating an increase in proinflammatory cytokines and, afterwards, the free radical scavenging and antioxidant characteristics of HA allow suppressing the inflammatory response during the healing process [1]. This dual role played during the inflammation phases depends on HA molecular mass indeed; in its native state, it generally exists as a high-molecular-mass polymer whereas, under inflammation, HA is more polydisperse, with a preponderance of lowermolecular-mass forms [2]. Besides, several studies shed light on other key roles played by HA in influencing cellular processes, for instance, morphogenesis, cancer progression, and metastasis [3]. Indeed, many HA fragments have been found in a wide range of carcinomas, lymphomas, melanocytic, and neuronal tumors; these fragments exhibit properties, not normally found in the native HA polymer, whose effects depend on the molecular size as, for instance, angiogenics or growth suppressing. The altered HA metabolism and the amount of itself in the tumor stroma or in the neoplastic cell compartment are strictly associated with invasion and local or distant metastases, impacting on the overall outcome [4]. HA and its derivatives have been also employed as anticancer 


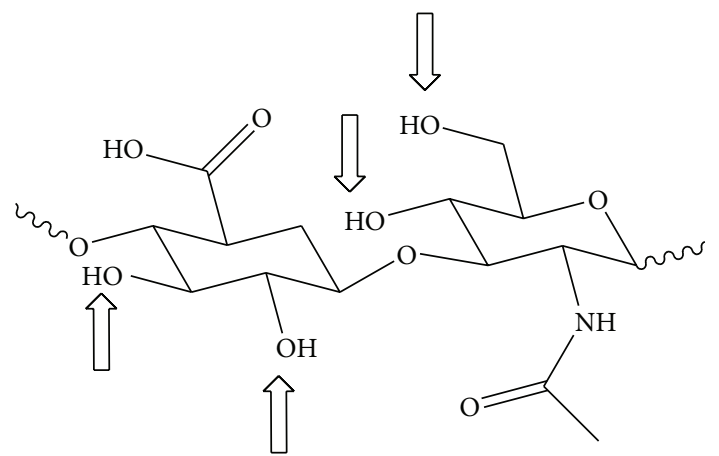

FIGURE 1: Functional groups of HA subjected to chemical modification.

drug carriers because of their ability to be recognized by specific cellular receptors overexpressed on tumor cells membrane $[5,6]$.

Although properties such as high biocompatibility, biodegradability, high hydrophilicity, and viscoelasticity led to considerable use of HA both in medicine and in cosmetics, in particular, in the treatment of joint problems and in the "tissue augmentation" [7], its solubility in water, rapid absorption, and short residence time in situ limit its application $[8,9]$. Moreover, exogenous HA is quickly degraded in vivo (half-life of $12-24 \mathrm{~h}$ ) by hydrolytic enzymes, that is, hyaluronidases (HAses). To ensure greater permanence in situ, the HA is generally subjected to chemical changes such as derivatization or, especially, cross-linking processes [10], which decrease the solubility in water and increase its resistance to enzymatic degradation. Currently on the market, there are several "stabilized" (cross-linked) and biocompatible gels based on HA $[8,9]$ and the research is continuously engaged in the development of new derivatives that have advantages over those already in use, in terms of both degradation times and native polymer biocompatibility conservation.

In this paper, we reported the preparation of the acetyl ester of HA (HA-Acet) (Figure 1), with the aim to prolong the effect and improve its radical scavenging, antioxidant properties and bioavailability in vitro. We have also evaluated the HA and HA-Acet cytotoxicity in three cellular lines, that is, murine monocyte/macrophage cell line (J774A.1), murine fibrosarcoma cells (WEHI-164), and human epithelial kidney cells (HEK-293), and, after that, the HA-Acet inhibition of NO release from J774A.1 murine macrophages has been studied in comparison with the free HA form.

\section{Material and Methods}

2.1. Chemistry. Unless stated otherwise, all reagents and compounds used were obtained from Sigma-Aldrich (Milan, Italy). The synthesis was made using sodium hyaluronate and its molecular weight $(90 \mathrm{kDa}$ ) was determined by GPC (gel permeation chromatography). GPC analysis of the sample was made at $35^{\circ} \mathrm{C}$ using a tool, equipped with UV detector, refractive index detector, and a set of four PPS columns (made of polystyrene) having pore dimensions, respectively, of $10^{5} \AA, 10^{4} \AA, 10^{3} \AA$, and $10^{2} \AA$ and particles size of $10 \mu \mathrm{m}$. It was used as a solvent tetrahydrofuran at a rate of flow of $1.0 \mathrm{~mL} / \mathrm{min}$. For the determination of the molecular weight a calibration curve was obtained. The progress of the reaction was controlled by thin-layer chromatography (TLC), performed on a $0.25 \mathrm{~mm}$ layer of silica gel 60 PF254 Merck. The final product (MW $94 \mathrm{kDa}$ ) was purified by column chromatography with silica gel (Merck silica gel) and characterized by ${ }^{1} \mathrm{H}$ NMR $(300 \mathrm{MHz})$ and the spectrum was recorded on Bruker 300 spectrometer.

2.2. Procedure for the Acetylation of Hyaluronic Acid (HAAcet). To a stirred cold solution $\left(0^{\circ} \mathrm{C}\right)$ of $500 \mathrm{mg}$ of sodium hyaluronate in $10 \mathrm{ml}$ of toluene were added a catalytic amount of 4-dimethylaminopyridine (DMAP) and an excess of acetic anhydride. The mixture was stirred at reflux, under nitrogen, for 24 hours and then concentrated under reduced pressure. The solid residue was purified by silica gel chromatography using dichloromethane and methanol $(9: 1)$ as eluent, obtaining the pure compound as white solid [11-14] (Scheme 1). ${ }^{1} \mathrm{H}$ $\operatorname{NMR}\left(\mathrm{CDCl}_{3}\right): \delta 2.10\left(\mathrm{~s}, 9 \mathrm{H}, 3 \mathrm{OCOCH}_{3}\right) ; 2.20-2.50(\mathrm{~m}$, $\left.6 \mathrm{H}, \mathrm{CH}_{2} \mathrm{OCOCH}_{3}, \mathrm{HNCOCH}_{3}\right) ; 4.10-4.40\left(\mathrm{~m}, 4 \mathrm{H}, 2 \mathrm{CH}_{2}\right)$; 4.45-5.50 (m, 9H, CH); 6.90-7.10 (br, 1H, OH); 8.10-8.50 (br, $1 \mathrm{H}, \mathrm{N} H)$.

2.3. Determination of Scavenging Effect on ABTS Radical Cation. The scavenging activity of native HA and HA-Acet towards the hydrophilic ABTS $\left(2,2^{\prime}\right.$-azinobis-(3ethylbenzothiazoline-6-sulfonic acid)) radical cation was assessed according to the literature with slight modifications [15]. ABTS was dissolved in water to a $7 \mathrm{mM}$ concentration; radical cation $\left(\mathrm{ABTS}^{\circ+}\right)$ was produced by reacting $\mathrm{ABTS}$ stock solution with $2.45 \mathrm{mM}$ potassium persulfate (final concentration) and allowing the mixture to stand in the dark at room temperature for $12-16 \mathrm{~h}$ before use. Because ABTS and potassium persulfate react stoichiometrically at a ratio of $1: 0.5$, this will result in incomplete oxidation of the ABTS. Oxidation of the ABTS commenced immediately, but the absorbance was not maximal and stable until more than $6 \mathrm{~h}$ had elapsed. The concentration of the resulting blue-green $\mathrm{ABTS}^{\text {++ }}$ solution was adjusted to an absorbance of $0.970 \pm$ 0.020 at $734 \mathrm{~nm}$. The radical was stable in this form for more than two days when stored in the dark at room temperature.

In the present study, $10 \mathrm{mg}$ of each sample was mixed with $5 \mathrm{~mL}$ of ABTS radical solution. The mixtures, protected from light, were incubated in a water bath at $37^{\circ} \mathrm{C}$ for $5 \mathrm{~min}$. The decrease of absorbance at $734 \mathrm{~nm}$ was measured at the endpoint of $5 \mathrm{~min}$. The antioxidant activity was expressed as a percentage of scavenging activity on ABTS radical according to

$$
\operatorname{Inhibition}(\%)=\frac{A_{0}-A_{1}}{A_{0}} \times 100 \text {, }
$$

where $A_{0}$ is the absorbance of a standard prepared in the same conditions, but without any sample, and $A_{1}$ is the absorbance of the hyaluronic acid samples. All samples were assayed in triplicate and data expressed as means $( \pm \mathrm{SD})$. 

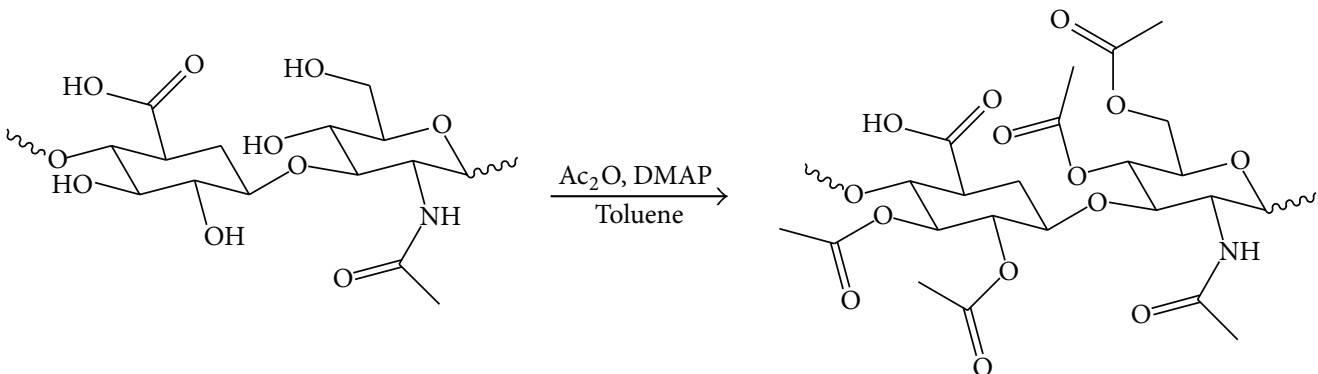

SCHeme 1: Acetylation of hyaluronic acid.

2.4. Nitric Oxide Radical (NO*) Scavenging Assay. The antiinflammatory activities of native $\mathrm{HA}$ and $\mathrm{HA}$-Acet were evaluated by performing the in vitro nitric oxide radical scavenging assay, in which $\mathrm{NO}^{\bullet}$ generated from sodium nitroprusside (SNP) was measured spectrophotometrically according to the method reported in literature with slight modifications [16]. $10 \mathrm{mg}$ of each sample was incubated with $1.0 \mathrm{~mL}$ of the reaction mixture, containing SNP $(5 \mathrm{mM})$ in phosphate-buffered saline ( $\mathrm{pH} 7.3)$, at $25^{\circ} \mathrm{C}$ for $3 \mathrm{~h}$ in front of a visible polychromatic light source ( $25 \mathrm{~W}$ tungsten lamp). The generated $\mathrm{NO}^{\bullet}$ radical interacted with oxygen to produce the nitrite ion $\left(\mathrm{NO}_{2}{ }^{-}\right)$which was assayed at $30 \mathrm{~min}$ intervals by mixing the incubation mixture with $1 \mathrm{~mL}$ of Griess reagent ( $1 \%$ sulfanilamide in $5 \%$ phosphoric acid and $0.1 \%$ naphthylethylenediamine dihydrochloride). The absorbance of the chromophore (purple azo dye) formed during the diazotization of nitrite ions with sulphanilamide and subsequent coupling with naphthylethylenediamine dihydrochloride was measured at $546 \mathrm{~nm}$. The anti-inflammatory activity was expressed as a percentage of scavenging activity according to (1). Each experiment was performed in triplicate and the data presented as average of three independent determinations.

2.5. In Vitro Bioavailability Studies. In vitro bioavailability studies were carried out in simulated gastric and intestinal fluids by performing a slight modified version of the dialysis tubing procedure $[17,18]$ with the aim to simulate the oral intake of native and acetylated hyaluronic acid. The dialysis tubing method is characterized by two consecutive enzymatic digestions: pepsin and pancreatin digestion, respectively. These steps are described as follows.

Pepsin Digestion. A $30 \mathrm{mg}$ amount of each sample was mixed with $1.0 \mathrm{~mL}$ of a $0.85 \mathrm{~N} \mathrm{HCl}$ solution containing $24000 \mathrm{U}$ of porcine pepsin per $\mathrm{mL}$. The obtained mixture was introduced into a dialysis bag (Spectrum Laboratories Inc., MWCO: 1214,000 Dalton, USA), which was then carefully closed and immersed inside a flask containing $5 \mathrm{~mL}$ of a $0.85 \mathrm{~N} 60 \mathrm{HCl}$ solution ( $\mathrm{pH} 1.0)$. The flask was then incubated in a shaking water bath at $37^{\circ} \mathrm{C}$ to simulate the human body temperature conditions for $2 \mathrm{~h}$.

Pancreatin Digestion. At the end of the $2 \mathrm{~h}$ pepsin digestion, the dialysis bag was opened and $11 \mathrm{mg}$ of amylase, $11 \mathrm{mg}$ of esterase, and $1.3 \mathrm{~mL}$ of a $0.8 \mathrm{M} \mathrm{NaHCO}_{3}$ solution containing
$22.60 \mathrm{mg}$ porcine pancreatin/mL were added to the peptic digesta. After the digesta and enzyme solution were well mixed, the dialysis bag was sealed at each end with clamps 70 and placed in a flask with $5 \mathrm{~mL}$ of buffer solution at $\mathrm{pH}$ 7.0. The flask was incubated in the shaking water bath at $37^{\circ} \mathrm{C}$ for a further $4 \mathrm{~h}$. After the pancreatin incubation time, the hydrolyzed hyaluronic acid was determined spectrophotometrically according to the literature [19]. Each experiment was performed in triplicate.

2.6. Cell Lines and Cultures. The murine monocyte/ macrophage cell line (J774A.1), murine fibrosarcoma cells (WEHI-164), and human epithelial kidney cells (HEK-293) were obtained from American Tissue Culture Collection (ATCC). Dulbecco's modified Eagle's medium (DMEM), penicillin/streptomycin HEPES, glutamine, fetal calf serum (FCS), and horse serum were from Euroclone (EurocloneCelbio, Pero, Milan, Italy). J774.A1 were grown in adhesion on Petri dishes and maintained at $37^{\circ} \mathrm{C}$ as previously described [20]. WEHI-164 and HEK-293 were maintained in adhesion on Petri dishes with DMEM supplemented with $10 \%$ heat-inactivated FCS, $25 \mathrm{mM}$ HEPES, $100 \mathrm{u} / \mathrm{mL}$ penicillin, and $100 \mu \mathrm{g} / \mathrm{mL}$ streptomycin.

2.7. Cell Viability Assay. J774.A1, WEHI-164, and HEK-293 $\left(3.5 \times 10^{4}\right.$ cells/well $)$ were plated on 96 -well microtiter plates and allowed to adhere at $37^{\circ} \mathrm{C}$ in a $5 \% \mathrm{CO}_{2}$ atmosphere for $2 \mathrm{~h}$. Thereafter, the medium was replaced with $50 \mu \mathrm{L}$ of fresh medium and $75 \mu \mathrm{L}$ aliquot of serial dilution of each test compound was added and then the cells were incubated for $72 \mathrm{~h}$. Serial dilution of 6-mercaptopurine (6MP) was added, as reference drug. In some experiments, HA or HA-Acet were added only to J774A.1 macrophages for $24 \mathrm{~h}$. Mitochondrial respiration, an indicator of cells viability, was assessed by the mitochondrial-dependent reduction of [3-(4,5-dimethylthiazol-2-yl)-2,5-phenyl-2H-tetrazolium bromide] (MTT) to formazan and cells viability was assessed as previously reported [21-28].

Briefly, $5 \mu \mathrm{L}$ of MTT $(5 \mathrm{mg} / \mathrm{mL})$ was added and the cells were incubated for an additional $3 \mathrm{~h}$. Thereafter, cells were lysed and the dark blue crystals solubilised with $100 \mu \mathrm{L}$ of a solution containing $50 \%(\mathrm{v}: \mathrm{v}) \mathrm{N}, N$-dimethylformamide and $20 \%$ (w:v) SDS with an adjusted $\mathrm{pH}$ of 4.5 [29]. The optical density (OD) of each well was measured with microplate 
spectrophotometer (Titertek, Multiskan MCC/340) equipped with a $620 \mathrm{~nm}$ filter. The viability of each cell line in response to treatment with tested compounds and 6-MP was calculated as $\%$ dead cells $=100-(\mathrm{OD}$ treated $/ \mathrm{OD}$ control $) \times 100 . \mathrm{IC}_{50}$ values (concentration that causes $50 \%$ growth inhibition) were determined [30].

2.8. $\mathrm{NO}_{2}{ }^{-}$Release from $\mathrm{J774A}$ Cells. Nitrite content $\left(\mathrm{NO}_{2}{ }^{-}\right)$, index of NO released by cells in the culture supernatant, was measured in J774A.1 cells. To stimulate nitric oxide (NO) release from macrophages, E. coli lipopolysaccharide (LPS, $\left.6 \times 10^{3} \mathrm{u} / \mathrm{mL}\right)$ was used [20]. Macrophages $\left(3.5 \times 10^{4}\right.$ cells/well) were plated on 96-well microtiter plates and allowed to adhere at $37^{\circ} \mathrm{C}$ in a $5 \% \mathrm{CO}_{2}$ atmosphere for $2 \mathrm{~h}$. HA and HA-Acet $(12.5-100 \mu \mathrm{mol} / \mathrm{L})$ were added for $1 \mathrm{~h}$ to cells and then coexposed to $1 \mu \mathrm{g} / \mathrm{mL}$ LPS for further $24 \mathrm{~h}$. $\mathrm{NO}_{2}{ }^{-}$amounts were measured by Griess reaction. Briefly, $100 \mu \mathrm{L}$ of cell culture medium was mixed with $100 \mu \mathrm{L}$ of Griess reagent-equal volumes of $1 \%$ (w:v) sulphanilamide in 5\% (v:v) phosphoric acid and $0.1 \%(\mathrm{w}: \mathrm{v})$ naphthylethylenediamine- $\mathrm{HCl}$-and incubated at room temperature for $10 \mathrm{~min}$, and then the absorbance was measured at $550 \mathrm{~nm}$ in a microplate reader Titertek (Dasit, Cornaredo, Milan, Italy). The amount of $\mathrm{NO}_{2}{ }^{-}$(as $\mu \mathrm{mol} / \mathrm{L}$ ) in the samples was calculated from a sodium nitrite standard curve.

2.9. Data Analysis. Data are reported as mean \pm standard error mean (s.e.m.) values of independent experiments, which were done at least three times, each time with three or more independent observations. Statistical analysis was performed by Student's $t$-test or analysis of variance test, and multiple comparisons were made by Bonferroni's test. A $P$ value less than 0.05 was considered significant.

\section{Results and Discussion}

3.1. Evaluation of the HA and HA-Acet Antioxidant and AntiInflammatory Activity. In the aim to establish the antioxidant and anti-inflammatory activities of HA and HA-Acet, their reactivity towards ABTS and nitric oxide $\left(\mathrm{NO}^{\circ}\right)$ was evaluated. ABTS is a preformed stable organic radical with absorption maximum at $734 \mathrm{~nm}$; nitric oxide $\left(\mathrm{NO}^{\circ}\right)$ is a pivotal proinflammatory mediator [31] and its contribution to oxidative damage is due to the reaction with superoxide to form the peroxynitrite anion, which is a potential strong oxidant that can decompose to produce ${ }^{\circ} \mathrm{OH}$ and $\mathrm{NO}_{2}$ [32]. In the present study, nitroprusside (SNP) was employed as a NO radical donor in the aim to evaluate the anti-inflammatory properties of native acid and acetylated hyaluronic acid. NO released from SNP, indeed, has a strong $\mathrm{NO}^{+}$character which can alter the structure and function of many cellular components. The scavenger ability of each sample (HA or HA-Acet) was evaluated in terms of radical reduction and data have been expressed as inhibition (\%) and reported in Table 1. Both samples were found to have good and comparable scavenging properties towards the selected radicals confirming that the acetylation of native HA does not affect the biological activity of this polysaccharide.
TABLE 1: Antioxidant and anti-inflammatory activity and in vitro bioavailability of HA and HA-Acet. Statistical analysis was performed using Student's $t$-test.

\begin{tabular}{lccc}
\hline \multirow{2}{*}{ Sample } & \multicolumn{2}{c}{ Inhibition (\%) } & Bioavailability (\%) \\
& ABTS & NO $^{\bullet}$ & $8 \pm 0.7$ \\
HA & $35 \pm 0.7$ & $77 \pm 0.9$ & $48 \pm 0.3^{*}$ \\
\hline
\end{tabular}

*indicates $P<0.001$ of HA-Acet versus HA.

TABLE 2: The $\mathrm{IC}_{50}$, expressed as $\mu \mathrm{mol} / \mathrm{L}$, value is the concentration of compound that affords a 50\% reduction in cell growth (after a $24 \mathrm{~h}$ incubation). J774.A1 = murine monocyte/macrophage cell lines. HEK-293 = human epithelial kidney cell lines. WEHI-164 = murine fibrosarcoma cell lines. 6-MP = 6-mercaptopurine.

\begin{tabular}{lccc}
\hline cmp & \multicolumn{3}{c}{$\mathrm{IC}_{50}(\mu \mathrm{M})$} \\
& J774.A1 & $\mathrm{HEK}-293$ & WEHI-164 \\
\hline HA-Acet & $>100$ & $>100$ & $>100$ \\
HA & $>100$ & $>100$ & $>100$ \\
$6-\mathrm{MP}$ & 1 & 1.5 & 1.4 \\
\hline
\end{tabular}

3.2. Bioavailability Studies. Dialysis tubing procedure is a fast and low cost method to evaluate the bioavailability of different kinds of compounds and, in this study, it was used in the aim to evaluate the bioavailability of native HA and HA-Acet. Bioavailability was defined as the percentage of tested HA and HA-Acet recovered in the bioaccessible fraction, after in vitro digestion, in relation to the original nondigested samples. This value can be calculated by the following equation:

$$
\left(\frac{\text { bioaccessible content }}{\text { total content }}\right) \times 100 \text {. }
$$

In the present study, we supposed that the chemical modification of native HA by introducing acetyl groups can improve the bioavailability of this biopolymer. The obtained data (Table 1) confirmed our supposition showing that the acetylation of native polysaccharide increases its bioavailability of six times. This higher value could be ascribable to the presence of acetyl moieties which make the polymeric backbone more lipophilic.

3.3. In Vitro Cytotoxicity and Anti-Inflammatory Experiments. We next evaluated the in vitro cytotoxic activity of HA and HA-Acet on three different cell lines (J774.A1, WEHI-164, and HEK-293). Our results clearly showed a low cytotoxicity, compared to 6-MP, on all the three used cell lines and also at the concentration range (i.e., $12.5-100 \mu \mathrm{mol} / \mathrm{L}$ ) used for NO release determination in J774A.1 cell line; HA or HA-Acet treatments did not elicit antiproliferative effects, as evidenced by the $\mathrm{IC}_{50}$ results shown in Table 2 .

The anti-inflammatory properties observed in previous experiments have been confirmed, as well, by testing HA and HA-Acet on J774A.1 murine macrophages. The latter were stimulated with LPS $(1 \mu \mathrm{g} / \mathrm{mL})$, in the presence or absence of HA or HA-Acet $(12.5-100 \mu \mathrm{mol} / \mathrm{L})$, to determine whether these compounds were able to modulate NO release. J774A.1 


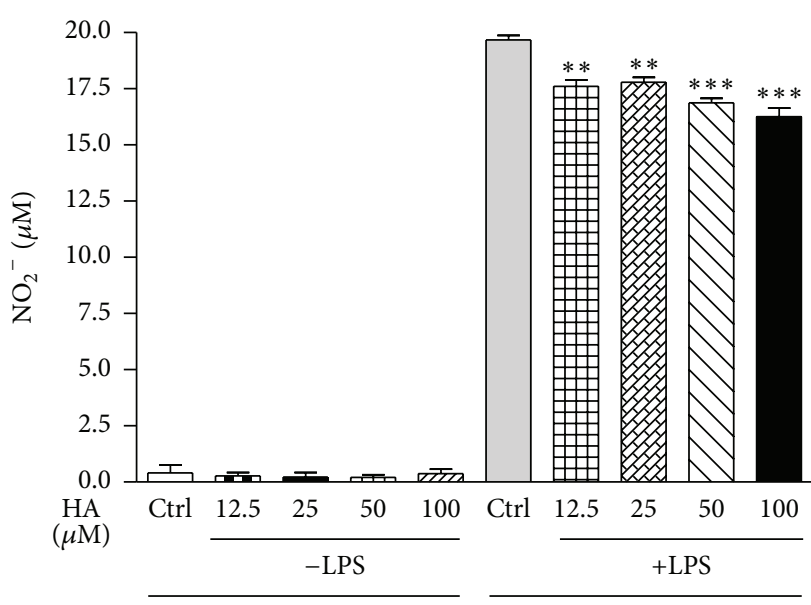

(a)

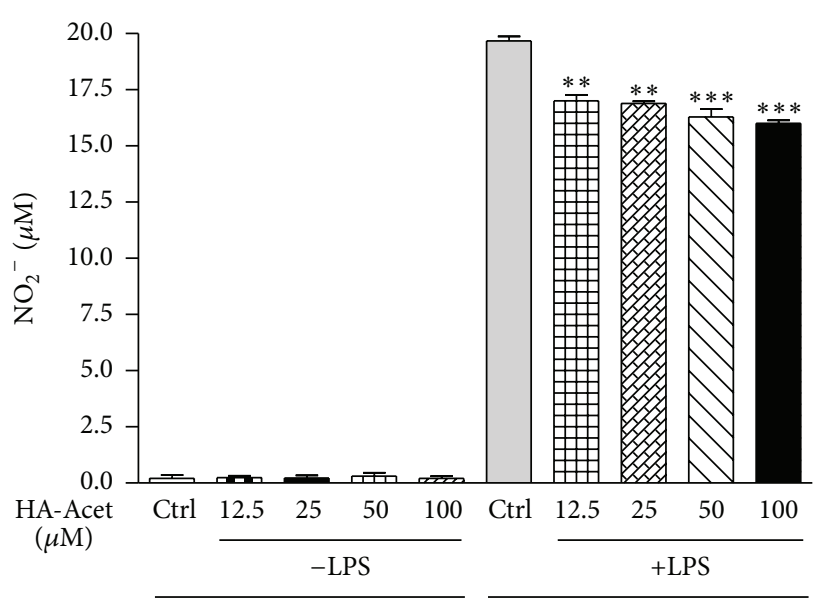

(b)

FIgure 2: Effect of HA (Panel (a)) and HA-Acet (Panel (b)) on NO release from J774A.1 macrophages stimulated with LPS for 24 h. ${ }^{* * *}$ and ${ }^{* *}$ denote $P<0.001$ and $P<0.01$, respectively, versus LPS alone.

cells challenged with LPS exhibited a high increase of NO accumulation, evaluated as nitrite, as shown in Figure 2, panels (a)-(b), whereas HA or HA-Acet, per se, did not affect basal $\mathrm{NO}$ production at the tested concentrations (12.5-100 $\mu \mathrm{mol} / \mathrm{L})$. Conversely, a significant reduction in NO release was detected in LPS-treated macrophages in presence of HA or HA-Acet at all tested concentrations, with a slight increase of HA-Acet ability in decreasing $\mathrm{NO}$ release from cells. We believe that this feature is most probably due to the better bioavailability and higher stability of HA-Acet with respect to the free HA form.

It is noteworthy that HA is usefully employed for the preparation of several derivatives which have been used as vector or delivery system for many molecules used in therapy mostly, but not only, for cancer treatment, due to the observation that HA-binding receptors such as cluster determinant 44 (CD44), receptor for hyaluronic acidmediated motility (RAHMM), and lymphatic vessel endothelial receptor-1 (LYVE-1) are dramatically overexpressed in cancer cells [33-35]. Under this point of view, acetylation is a simple and suitable technique which allows increasing the hydrophobicity without impairing the ability of HAreceptors to interact with the acetylated-HA [36]. Moreover, it should be considered that generation of ROS (reactive oxygen species) plays a key role in human diseases and aging process and that $\mathrm{HA}$ is involved in the activation and modulation of the inflammatory response, including a scavenging activity towards ROS, such as hydroxyl radical $\left({ }^{\circ} \mathrm{OH}\right)$. On the other hand, inhibition of tumor cells and protection of tissue from free radical damage have also been attributed to a mixture of hyaluronic acid fragments and, in recent years, several reports described that HA exerts antiageing effect with potential antioxidant properties both in vitro and in vivo [37-39]. The efficacy ofthese considerable properties is related to many factors and, more strictly, to the catabolism of $\mathrm{HA}$ in the considered biologic environment. The major actors involved in its degradation are hyaluronidases, which would diminish its presence in the extracellular environment, so that the strategy to chemically modify HA (e.g., by acetylation), most importantly without altering the interaction with its receptors, has been pursued over time in order to increase its stability, bioavailability, and, lastly, its effects. Our results are promising for further studies addressed to a better understanding of the interactions of HA-Acet with biological molecules.

\section{Conclusions}

In this study we reported the synthesis of an acetylated HA derivative which exhibited a better bioavailability and stability with respect to the HA free form. These features have been confirmed, as well, by the evaluation of the NO release inhibition from murine monocyte/macrophage cell lines (J774.A1). HA-Acet showed a low cytotoxicity in all the three cell lines, at least at the drug doses used in the experiments and, moreover, a slight but significant increased antiinflammatory activity, dose-dependent, has been evidenced. Our results bring a new contribution to the studies focused on the several biological properties and therapeutic uses of HA.

\section{Conflict of Interests}

The authors declare that there is no conflict of interests regarding the publication of this paper.

\section{Authors' Contribution}

Carmela Saturnino and Maria Stefania Sinicropi equally contributed to this work.

\section{Acknowledgments}

This work was supported by the Programma Operativo Nazionale (PON) Ricerca e Competività per le Regioni della 
Convergenza, 2007/2013-CCI: 2007IT161PO006, to AC and OIP, and by Commissione Europea, Fondo Sociale Europeo (FSE 2007/2013-PROGRAMMA ARUE), and Regione Calabria to DI.

\section{References}

[1] J. Voigt and V. R. Driver, "Hyaluronic acid derivatives and their healing effect on burns, epithelial surgical wounds, and chronic wounds: a systematic review and meta-analysis of randomized controlled trials," Wound Repair and Regeneration, vol. 20, pp. 317-331, 2012.

[2] D. H. Jiang, J. R. Liang, and P. W. Noble, "Hyaluronan as an immune regulator in human diseases," Physiological Reviews, vol. 91, pp. 221-264, 2011.

[3] N. Afratis, C. Gialeli, D. Nikitovic et al., "Glycosaminoglycans: key players in cancer cell biology and treatment," FEBS Journal, vol. 279, pp. 1177-1197, 2012.

[4] R. K. Sironen, M. Tammi, R. Tammi, P. K. Auvinen, M. Anttila, and V. M. Kosma, "Hyaluronan in human malignancies," Experimental Cell Research, vol. 317, pp. 383-391, 2011.

[5] W. Park, K. S. Kim, B. C. Bae, Y. H. Kim, and K. Na, "Cancer cell specific targeting of nanogels from acetylated hyaluronic acid with low molecular weight," European Journal of Pharmaceutical Sciences, vol. 40, no. 4, pp. 367-375, 2010.

[6] A. Speranza, C. Pellizzaro, and D. Coradini, "Hyaluronic acid butyric esters in cancer therapy," Anti-Cancer Drug, vol. 16, pp. 373-379, 2005.

[7] A. Fakhari and C. Berkland, "Applications and emerging trends of hyaluronic acid in tissue engineering, as a dermal filler and in osteoarthritis treatment," Acta Biomaterialia, vol. 9, pp. 70817092, 2013.

[8] S. L. Matarasso, "Understanding and using hyaluronic acid," Aesthetic Surgery Journal, vol. 24, pp. 361-364, 2004.

[9] F. Duranti, G. Salti, B. Bovani, M. Calandra, and M. L. Rosati, "Injectable hyaluronic acid gel for soft tissue augmentation. A clinical and histological study," Dermatologic Surgery, vol. 24, no. 12, pp. 1317-1325, 1998.

[10] J. Wohlrab, D. Wohlrab, and R. H. Neubert, "Comparison of noncross-linked and cross-linked hyaluronic acid with regard to efficacy of the proliferative activity of cutaneous fibroblasts and keratinocytes in vitro," Journal of Cosmetic Dermatology, vol. 12, pp. 36-40, 2013.

[11] S. V. Shelke, G. P. Gao, S. Mesch et al., "Synthesis of sialic acid derivatives as ligands for the myelin-associated glycoprotein (MAG)," Bioorganic \& Medicinal Chemistry, vol. 15, no. 14, pp. 4951-4965, 2007.

[12] C. Saturnino, C. Palladino, A. Capasso et al., "Synthesis of oleylphosphonates as potential inhibitors of DAGL and MAGL. Part I," Pharmacologyonline, vol. 1, pp. 365-375, 2011.

[13] S. Ferorelli, C. Franchini, F. Loiodice et al., "Lipase-mediated kinetic resolution of rigid clofibrate analogues with lipidmodifying activity," Tetrahedron: Asymmetry, vol. 12, pp. 853$862,2001$.

[14] L. di Nunno, C. Franchini, A. Scilimati, M. S. Sinicropi, and P. Tortorella, "Chemical and chemoenzymatic routes to 1-(benzothiazol-2-ylsulfanyl)-3-chloropropan-2-ol, a precursor of drugs with potential beta-blocker activity," Tetrahedron: Asymmetry, vol. 11, pp. 1571-1583, 2000.

[15] F. Puoci, R. Malanchin, C. Piangiolino et al., "Maca flour: a powerful ingredient for functionally enhanced bread," International Food Research Journal, vol. 20, pp. 1597-1604, 2013.
[16] L. Marcocci, J. J. Maguire, M. T. Droy-Lefaix, and L. Packer, “The nitric oxide-scavenging properties of Ginkgo biloba extract EGb 761," Biochemical and Biophysical Research Communications, vol. 201, no. 2, pp. 748-755, 1994.

[17] F. R. Lupi, D. Gabriele, N. Baldino, P. Mijovic, O. I. Parisi, and F. Puoci, "Olive oil/policosanol organogels for nutraceutical and drug delivery purposes," Food \& Function, vol. 4, pp. 1512-1520, 2013.

[18] A. Chimento, M. Sala, I. M. Gomez-Monterrey et al., "Biological activity of 3-chloro-azetidin-2-one derivatives having interesting antiproliferative activity on human breast cancer cell lines," Bioorganic and Medicinal Chemistry Letters, vol. 23, pp. 64016405, 2013.

[19] J. A. Marsh, F. R. Hallett, and R. R. Owen, "A comparison of techniques for the quantitative analysis of hyaluronic acid in equine synovial fluid, Canadian journal of comparative medicine," Revue Canadienne de Medecine Comparee, vol. 40, pp. 202-208, 1976.

[20] G. Bianco, R. Russo, S. Marzocco, S. Velotto, G. Autore, and L. Severino, "Modulation of macrophage activity by aflatoxins B1 and B2 and their metabolites aflatoxins M1 and M2," Toxicon, vol. 59, pp. 644-650, 2012.

[21] G. Autore, A. Caruso, S. Marzocco et al., "Acetamide derivatives with antioxidant activity and potential anti-inflammatory activity," Molecules, vol. 15, pp. 2028-2038, 2010.

[22] G. Cioffi, R. Sanogo, A. Vassallo et al., "Pregnane glycosides from Leptadenia pyrotechnica," Journal of Natural Products, vol. 69, pp. 625-635, 2006.

[23] A. Caruso, A. Chimento, H. El-Kashef et al., "Antiproliferative activity of some 1,4-dimethylcarbazoles on cells that express estrogen receptors: part I," Journal of Enzyme Inhibition and Medicinal Chemistry, vol. 27, pp. 609-613, 2012.

[24] E. Sirignano, C. Saturnino, A. Botta et al., "Synthesis, characterization and cytotoxic activity on breast cancer cells of new half-titanocene derivatives," Bioorganic \& Medicinal Chemistry Letters, vol. 23, no. 11, pp. 3458-3462, 2013.

[25] M. Sala, A. Chimento, C. Saturnino et al., "Synthesis and cytotoxic activity evaluation of 2,3-thiazolidin-4-one derivatives on human breast cancer cell lines," Bioorganic \& Medicinal Chemistry Letters, vol. 23, pp. 4990-4995, 2013.

[26] C. Saturnino, E. Sirignano, A. Botta et al., "New titanocene derivatives with high antiproliferative activity against breast cancer cells," Bioorganic and Medicinal Chemistry Letters, vol. 24, pp. 136-140, 2014.

[27] A. Panno, M. S. Sinicropi, A. Caruso et al., "New trimethoxybenzamides and trimethoxyphenylureas derived from dimethylcarbazole as cytotoxic agents. Part I," Journal of Heterocyclic Chemistry, 2014.

[28] A. Carocci, A. Catalano, C. Bruno et al., " $N$ (Phenoxyalkyl)amides as $\mathrm{MT}_{1}$ and $\mathrm{MT}_{2}$ ligands: Antioxidant properties and inhibition of $\mathrm{Ca}^{2+} / \mathrm{CaM}$-dependent kinase II," Bioorganic \& Medicinal Chemistry, vol. 21, no. 4, pp. 847-851, 2013.

[29] A. W. Opipari, H. M. Hu, R. Yabkowitz, and V. M. Dixit, “The A20 zinc finger protein protects cells from tumor necrosis factor cytotoxicity," Journal of Biological Chemistry, vol. 267, pp. 1242412427, 1992.

[30] L. di Donna, D. Iacopetta, A. R. Cappello et al., "Hypocholesterolaemic activity of 3-hydroxy-3-methyl-glutaryl flavanones enriched fraction from bergamot fruit (Citrus bergamia): “in vivo" studies," Journal of Functional Foods, vol. 7, pp. 558-568, 2014. 
[31] Y. S. Huang and S. C. Ho, "Polymethoxy flavones are responsible for the anti-inflammatory activity of citrus fruit peel," Food Chemistry, vol. 119, pp. 868-873, 2010.

[32] L. Marcocci, J. J. Maguire, M. T. Droylefaix, and L. Packer, "The nitric oxide-scavenging properties of Ginkgo biloba extract EGb 761," Biochemical and Biophysical Research Communications, vol. 201, pp. 748-755, 1994.

[33] A. Aruffo, I. Stamenkovic, M. Melnick, C. B. Underhill, and B. Seed, "CD44 is the principal cell surface receptor for hyaluronate," Cell, vol. 61, pp. 1303-1313, 1990.

[34] S. H. Bhang, N. Won, T. J. Lee et al., "Hyaluronic acid-quantum dot conjugates for in vivo lymphatic vessel imaging," ACS nano, vol. 3, pp. 1389-1398, 2009.

[35] S. Ganesh, A. K. Iyer, D. V. Morrissey, and M. M. Amiji, "Hyaluronic acid based self-assembling nanosystems for CD44 target mediated siRNA delivery to solid tumors," Biomaterials, vol. 34, pp. 3489-3502, 2013.

[36] W. Park, K. S. Kim, B. C. Bae, Y. H. Kim, and K. Na, "Cancer cell specific targeting of nanogels from acetylated hyaluronic acid with low molecular weight," European Journal of Pharmaceutical Sciences, vol. 40, pp. 367-375, 2010.

[37] H. D. Halicka, V. Mitlitski, J. Heeter, E. A. Balazs, and Z. Darzynkiewicz, "Attenuation of the oxidative burst-induced DNA damage in human leukocytes by hyaluronan," International Journal of Molecular Medicine, vol. 23, pp. 695-699, 2009.

[38] G. M. Campo, A. Avenoso, S. Campo, A. D’Ascola, A. M. Ferlazzo, and A. Calatroni, "The antioxidant and antifibrogenic effects of the glycosaminoglycans hyaluronic acid and chondroitin-4-sulphate in a subchronic rat model of carbon tetrachloride-induced liver fibrogenesis," Chemico-Biological Interactions, vol. 148, no. 3, pp. 125-138, 2004.

[39] D. Jiang, J. Liang, and P. W. Noble, "Hyaluronan as an immune regulator in human diseases," Physiological Reviews, vol. 91, pp. 221-264, 2011. 

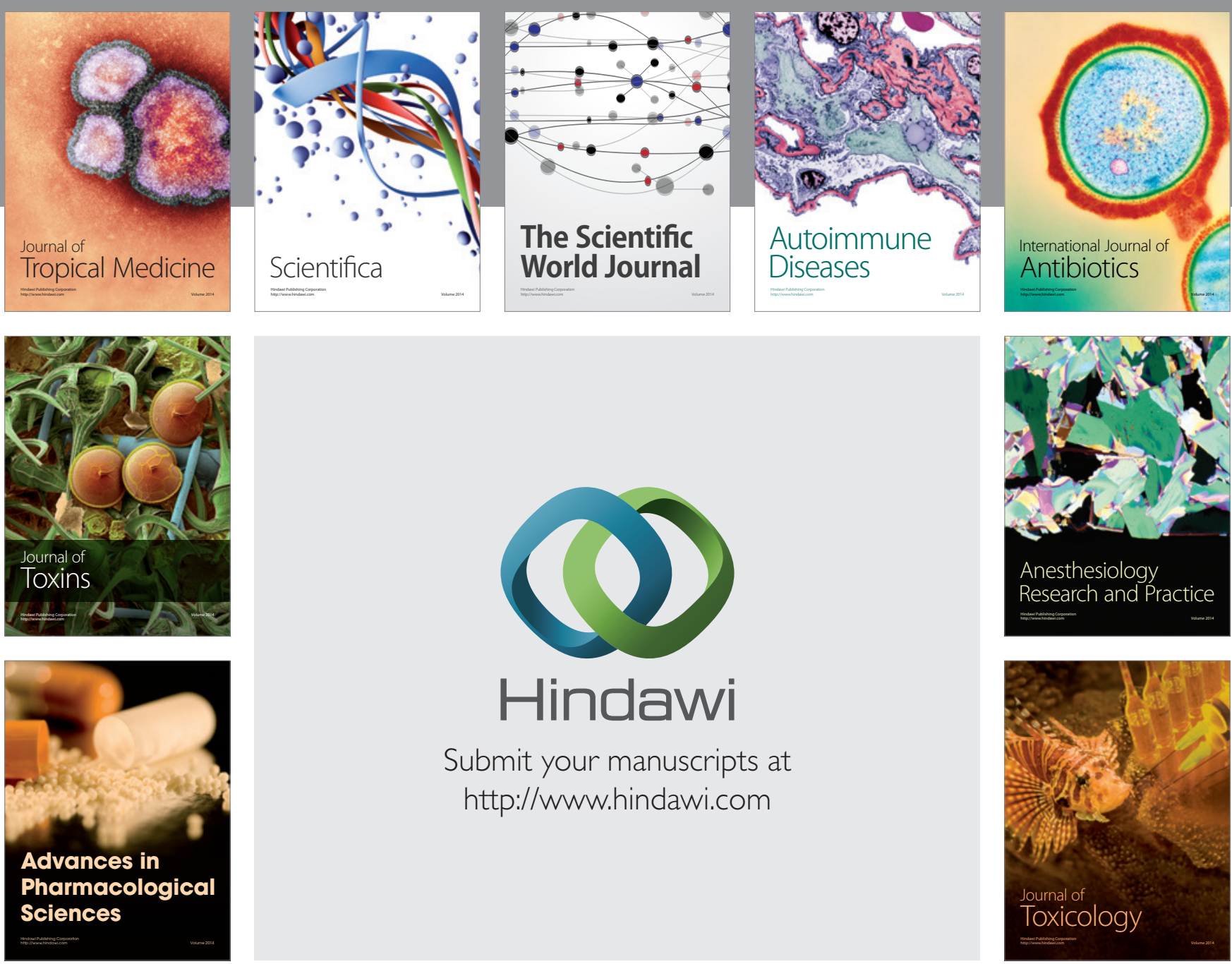

\section{Hindawi}

Submit your manuscripts at

http://www.hindawi.com
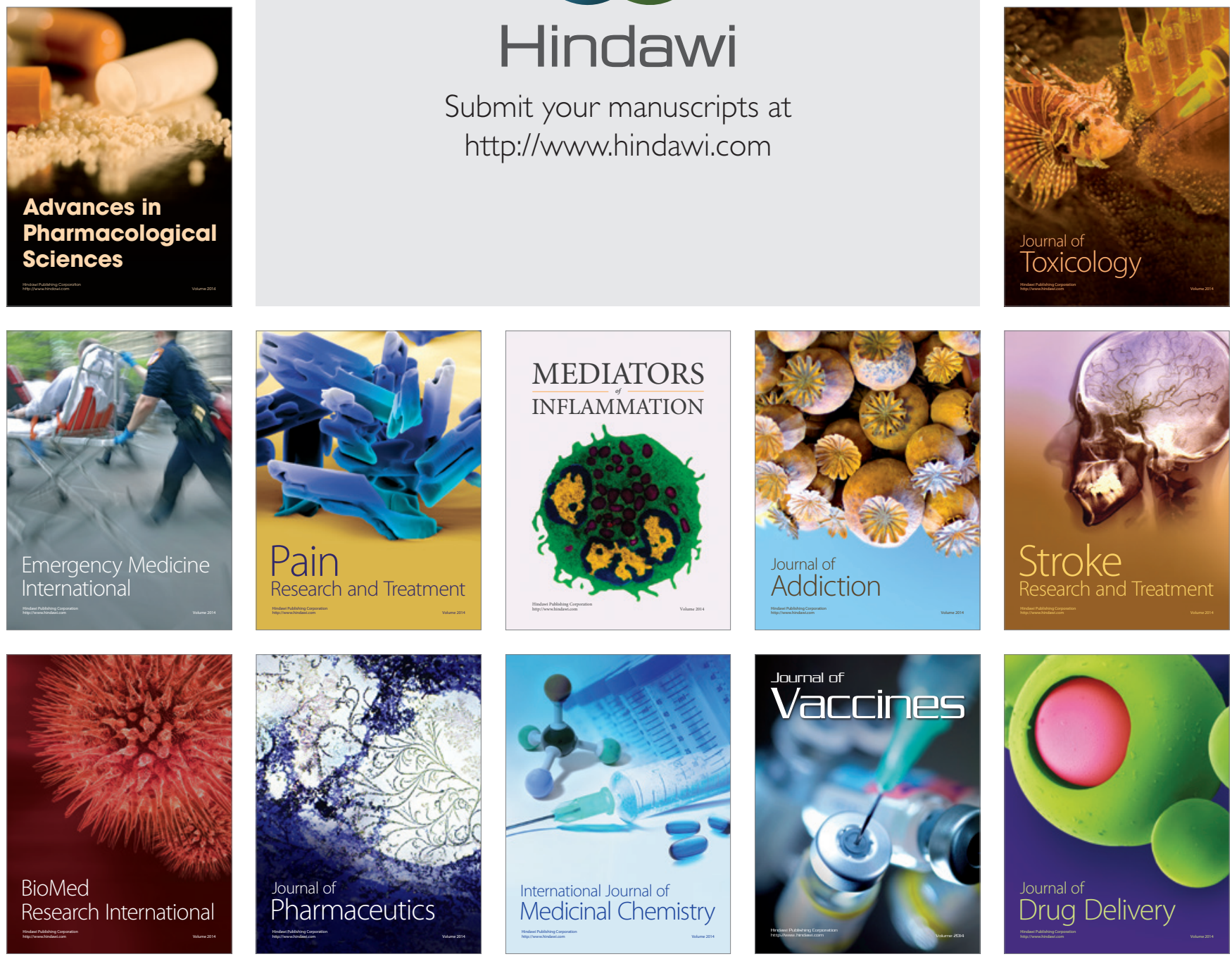